\title{
Progressive closure planning at the Magellan Mine — providing some certainty in uncertain times: a case study
}

\author{
K.G.A. Blackman Magellan Metals Pty Ltd, Australia \\ N. Burne Outback Ecology, Australia \\ I.C. Mitchell Outback Ecology, Australia \\ H.W.B. Lacy Outback Ecology, Australia
}

S. Mackenzie Mine Earth, Australia

\begin{abstract}
Closure planning in the mining industry has been typically left until near the end of mine life, often leaving little time, financial provision or resources for effective closure planning and implementation. Ideally proponents would commit resources and time for closure planning from the commencement of operations to optimise financial return through effective planning and enhanced efficiency.

Limitations associated with closing a mine in an unplanned manner include inadequate financial provision, substandard and expensive rehabilitation, and limited access to adequate equipment and materials. The lack of time to trial rehabilitation methods, the absence of corporate memory due to personnel departures, coupled with an extended post-closure monitoring and management period, will all contribute to prolonged tenement relinquishment and continuing liability for proponents.
\end{abstract}

Magellan Metals Pty Ltd (the Company) owns and operates an open-cut lead carbonate mine and processing facility, located approximately $30 \mathrm{~km}$ west of Wiluna in the mid-west region of Western Australia, which is approximately $730 \mathrm{~km}$ northeast of Perth. The Company required a dynamic system to facilitate early and effective rehabilitation and closure planning over the life of the mine. Specifically, the Company required a closure system that would facilitate the establishment of closure planning tasks, allowing for tracking of these tasks and for ongoing performance monitoring.

This paper describes a change in direction in mine decommissioning planning through a case study describing the development and implementation of a progressive rehabilitation and closure system. The system applied is a spatially managed closure planning system that allows proponents to track and measure closure progress via a web-based platform. Dedicated closure tasks are established within the system and the proponent is able to allocate resources against those tasks, through standard geographic information systems (GIS) information and aerial photography. The system also integrates active links to relevant supporting documentation.

The system has allowed the Company to better estimate its closure liability in an uncertain and challenging financial, political and environmental climate. Its implementation has also allowed the Company to demonstrate closure planning progress to internal and external stakeholders.

\section{Introduction}

Planned mine closures are rare; involuntary mine closures are more common and are related not only to the depletion of ore reserves, but also to economic instability, regulatory intervention, geological and technical issues, policy changes, social and community pressures, and environmental incidents (DITR, 2006). With confidence in capital markets currently weak and prices received for product low, the potential for unplanned mine closures has increased, and is likely to further increase as the follow on effects of the 2008/2009 global economic crisis impact the mining industry. The value of effective closure planning and implementation has increased, and while commodity pressure and high-capital commitments may preclude the continual operation of a mine, these economic constraints may also mean there is insufficient financial provision to undertake required closure and rehabilitation activities. 
The Company operates an open-cut lead carbonate mine and processing facility approximately $730 \mathrm{~km}$ northeast of Perth in Western Australia, near Wiluna. The mine was commissioned in October 2005 and produces lead carbonate concentrate for export. Lead carbonate is used in the production of lead-acid batteries for vehicles, critical infrastructure systems and as storage for renewable energy systems.

The Company required a closure system which would provide clarity in designating closure planning tasks, allowed for tracking of these tasks, and for performance monitoring over time. To achieve these objectives the Company engaged a consultancy to implement a proprietary progressive rehabilitation and closure system.

\section{Unplanned mine closure is an industry reality}

Ideally mines only close when their ore reserves have been extracted and a suitable mine closure plan has been developed and progressively implemented. Unfortunately planned closures are rare. In the past two decades almost $25 \%$ of mine closures in Australia have been unplanned (Laurence, 2002).

The 2008/2009 global economic crisis has led to sharply deteriorating global economic conditions, causing recession in many developed countries. The current global financial crisis may well be a link to premature closure as the number of unplanned mine closures has increased, and some mines have moved on to care and maintenance, which can be a precursor to full closure. For 2008, and into the first quarter of 2009, there were over 100 premature mine closures internationally (Figure 1) (D. Laurence, pers. comm., 2009).

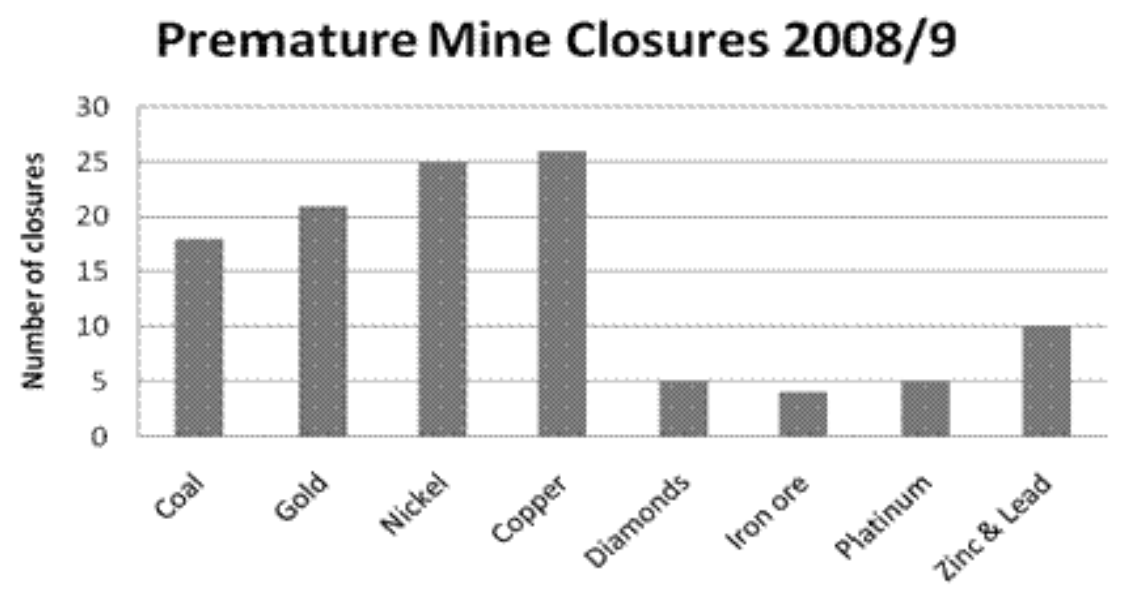

Figure 1 Premature mine closures by commodity 2008 to April 2009 (D. Laurence, pers. comm., 2009)

Given closure planning is typically left until near the end of mine life and given the recent acceleration in the number of mine closures, there is even less time for effective closure planning and implementation. As closure inherently involves a large-scale reduction of existing operational staff and contractors, the corporate memory required for effective planning and implementation may be lost.

There is an increasing expectation on mining companies to ensure there is adequate financial provision to reflect the real cost of closure and rehabilitation, since mine closure takes place when there is typically no return from the operation and there may be little economic value in the remaining assets (ANZMEC/MCA, 2000). This expectation will only increase in light of the global economic crisis. Boards are increasingly required to report on liabilities and closure costs and as matter of general due diligence. The International Financial Reporting Standards (IFRS) now have greater focus on mine closure liabilities, including environmental and restoration liabilities (PWC, 2007). In accordance with the IFRS, a progressive approach to mine closure effectively allows costs to be progressively allocated, budgeted, and reported during the life of mine. As closure tasks are completed, their individual cost can be reconciled, and progress against liability reduction can be demonstrated within an organisation. 


\section{Context for the Company}

The Company required more than a traditional mine closure plan; they required a dynamic system in order to facilitate progressive rehabilitation and closure planning over the mine life. An approach was required that would assist the establishment of closure tasks, provide a tracking system for the tasks and for monitoring of performance over time. The desired approach also had to include a document management system to integrate the large volume of reports, photographs and data that is generated over time and is critical for closure planning. The majority of closure plans do not often make provision for the establishment or tracking of tasks. Furthermore, it is difficult for traditional closure plans to be progressively updated as additional technical, regulatory, environmental and/or social information becomes available. Effective mine closure planning and implementation requires ongoing allocation of resources, delineation of responsibilities and project management, all components that are often not embedded within a traditional closure plan.

Progressive rehabilitation and closure planning represented a method that allowed the Company to identify areas of high-risk early in the process, and reduce its environmental liabilities by progressive closure planning and rehabilitation. Therefore, in the event of an unplanned mine closure, a closure plan would be in place, rehabilitation would be underway, closure liabilities understood, and the likelihood of expedient tenement relinquishment would be more likely and the early relinquishment of tenements will assist with cash flow as environmental bonds are released. It was important to the Company that any system applied had been developed in accordance with the principles of the 'Strategic Framework for Mine Closure' (ANZMEC/MCA, 2000), and the system as described in this case study was known to do so (Mackenzie et al., 2008).

\section{$4 \quad$ Progressive rehabilitation and closure}

Progressive rehabilitation is a term used to encourage mine rehabilitation activities. The concept was first alluded to as a potentially applicable concept for mine closure in the 'Strategic Framework for Mine Closure' (ANZMEC/MCA, 2000). The first Mine Decommissioning manual (Environment Australia, 2002) further developed and discussed systemised decommissioning ideas, and this process and its application was described at a series of workshops and conferences across Australia (Lacy and Koontz, 2002), as active progressive decommissioning systems were being put in place at mines in the Goldfield regions of Western Australia (Lacy et al., 2002).

However these early progressive systems described above were restricted in their application, as they are hardcopy systems and difficult to update. The commitment to these systems was limited to the individuals who implemented them. These systems were not web-based, fully live GIS systems, and therefore most became unsupported and redundant. The progressive closure and rehabilitation system described in this case study has been specifically designed to overcome that flaw by making it accessible, easily utilised by staff and applicable in the long term, with the aim that active closure planning will be maintained.

\section{$5 \quad$ Key system features}

The Progressive Rehabilitation and Closure $\left(\mathrm{PRAC}^{\circledR}\right)$ system is a spatially managed closure planning system that allows proponents to track and measure closure progress via a web-based platform. As a web-based system, with a GIS interface, it facilitates a shift from static closure plans (often hardcopy format) to a system that is dynamic and electronic based. The system enables the management of tasks and documents in a spatial context, using standard GIS information and aerial imagery. Dedicated closure tasks are established within the system and the proponent is able to allocate resources against those tasks, through standard GIS information, aerial photography, and integrated documentation. The current knowledge base for any defined area forms the platform from which a rehabilitation and closure strategy for that area can be established. Through the process of gap analysis, tasks can be identified to fill gaps and ultimately refine the rehabilitation and closure strategy for specific areas. This enables early identification of high risk priorities and allows progressive reduction of environmental liabilities.

The system as a web-based application can be accessed securely from a computer anywhere in the world that has internet access. The strength of the system is that tasks and documents can be managed in a spatial context, using standard GIS information and aerial imagery. 
Web-based GIS software is fast becoming the standard medium for managing location based data. There are a number of reasons why this is happening:

- Free GIS software such as Google Earth has made GIS technologies accessible to anyone who has an internet connection.

- Aerial imagery is becoming less expensive to capture and image quality is improving.

- Internet speeds are increasing making it easier to run web-based applications.

- Data storage is becoming simpler and less expensive, making it easier to store large volumes of data required to run GIS software.

\section{Case study}

\subsection{Mining operations and setting}

Portions of the mine's tenements lie within operational pastoral leases. The climate of the region is semiarid, affected by high intensity summer storms either of conventional derivation or as degrading tropical cyclones, generally accompanied by widespread heavy rainfall. The mine area is characterised by low hills and gently undulating plateaus flowing down to calcrete drainage plains. The mine is situated on a sloping plateau surrounded by calcareous drainage lines and saline soils (Keith Lindbeck and Associates, 1999). A quartz-clay breccia found in the Yandal Formation hosts the lead mineralisation at the mine. This breccia has a high porosity, and can be weakly ferruginous and weakly calcareous (DE Cooper and Associates Pty Ltd, 1999). Vegetation in the region is sparsely dispersed and dominated by Mulga scrublands, with the occasional taller shrubs or trees species. Vegetation reflects a long history of stock grazing, and is generally classed as having poor to moderate health. Fauna identified around the mine generally reflects the poor health of vegetation, with small numbers of individuals caught or observed during surveys. Generally, the species present in the mine area are limited due to the impact of grazing (Keith Lindbeck and Associates, 1999).

The lead-carbonate mine employs shallow open pit mining techniques and has an estimated mine life of approximately ten years (Keith Lindbeck and Associates, 1999). Lead-carbonate ore is fed through a conventional crushing and grinding circuit. A flotation circuit produces concentrated lead carbonate which is packaged in sealed bulk bags and transported in locked shipping containers by road and rail for export. The mine comprises the following key features as shown in Figure 2:

- Two open cut pits with a current estimated depth of $40 \mathrm{~m}$ (Magellan and Cano).

- Tailings storage facility ( 2 cells) encompassing an area of 66 ha.

- Waste rock dump with a final estimated footprint 138 ha.

- Run of mine pad adjacent to the processing plant.

- Process and raw water ponds.

- Lead processing facilities.

- Concentrate storage facilities.

- Dual fuel power station and associated infrastructure.

- Reverse osmosis plant for production of potable water.

- A number of workshops.

- Sewage facilities, located adjacent the accommodation village and mine offices.

- Landfills.

- Mine offices and accommodation facilities for up to 200 personnel.

- Haul and access roads.

- Drill sites and other exploration associated disturbances. 


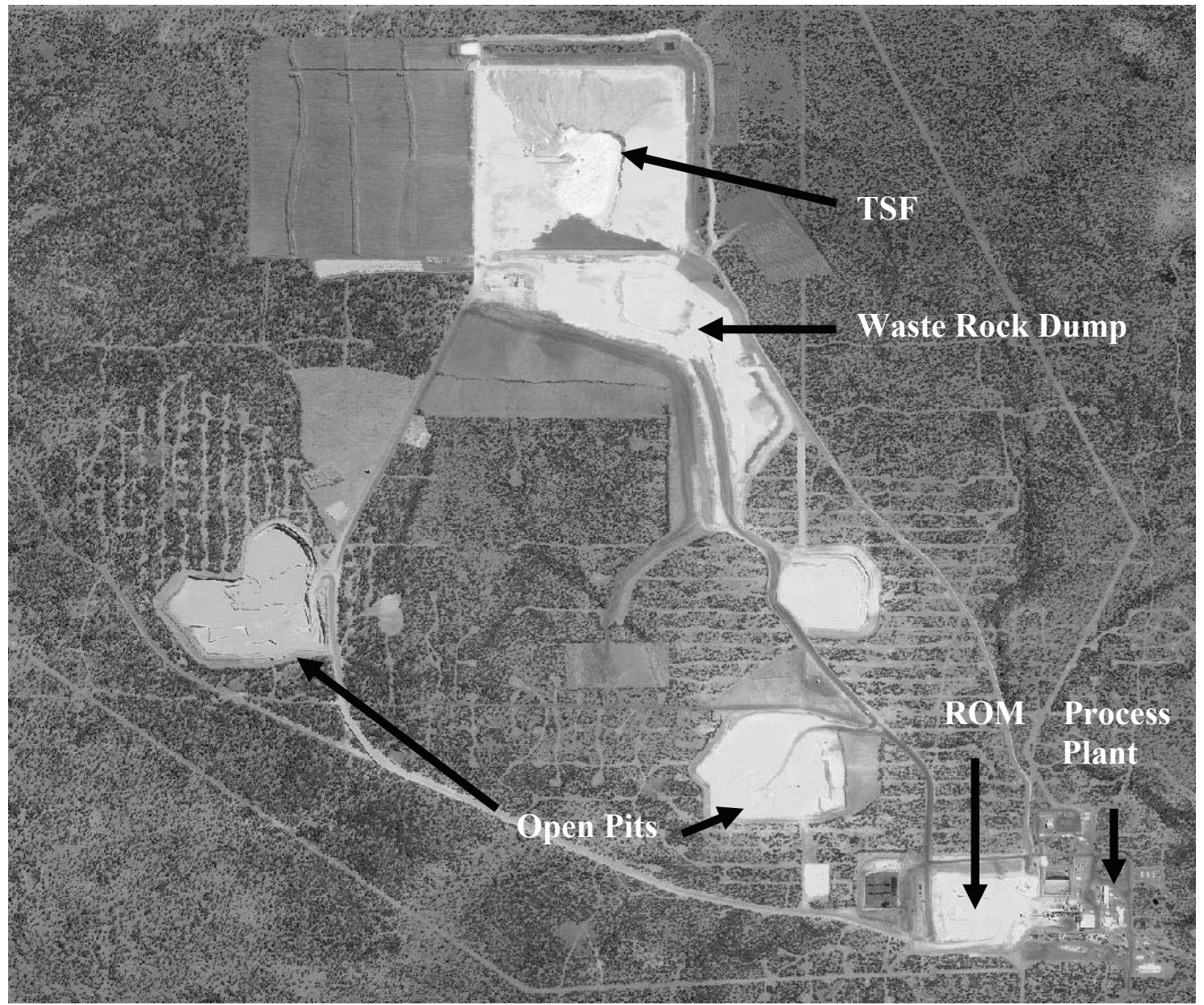

Figure 2 Aerial image of the mine showing extent of project activities

\subsection{Mine closure system development}

Firstly the mine area was divided into physically distinct features then all available and relevant information was reviewed for each feature and summarised into a knowledge base document. Through the creation of the knowledge base document, corresponding knowledge gaps were identified that may limit the development of effective closure and rehabilitation plans for each feature. Investigative and rehabilitation tasks were created to close each knowledge gap, and prioritised over the life of mine to create a progressive rehabilitation and closure strategy for each feature.

The system manages the various tasks (investigative, monitoring or rehabilitation tasks) for each feature on a mine. Once established, tasks can be scheduled logically over time. Tasks can be managed via the GIS interface or through an interactive Gantt chart. Tasks are marked as not-complete, in-progress or completed, allowing effective tracking of achievements over time and re-establishment of planning priorities (Figure 3).

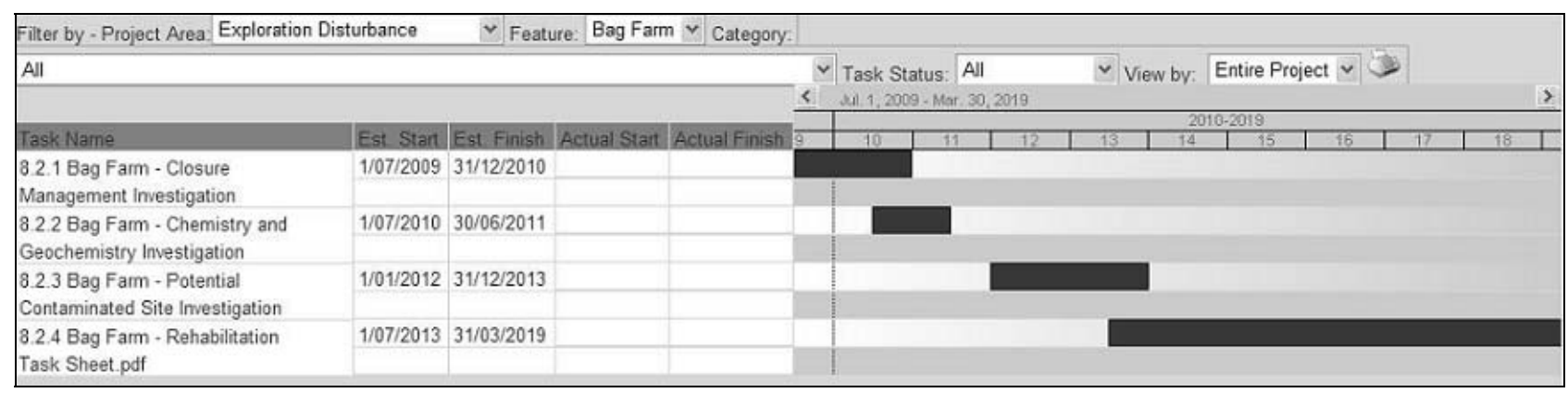

Figure 3 Gantt chart of investigative and rehabilitation tasks for the Bag Farm 
When viewed through the Gantt chart, tasks can be sorted by the project area they relate to, their status and/or their category. There are six different categories of tasks, enabling quick reference to similar tasks to optimise the allocation of specialist resources. Task queries can be generated for reporting requirements. In addition, tasks can be emailed or printed by a project manager for the personnel responsible for their completion.

Additionally, the system hosts electronic copies of all relevant and referenced documentation including monitoring data, historic approvals documents, knowledge base and gap documentation, and related reports. Copies of the documents are held in a secure register. Links to specific documents are established for each project area and are accessible through a global search function (Figure 4). This function allows the user to search and access all documents hosted within the system.

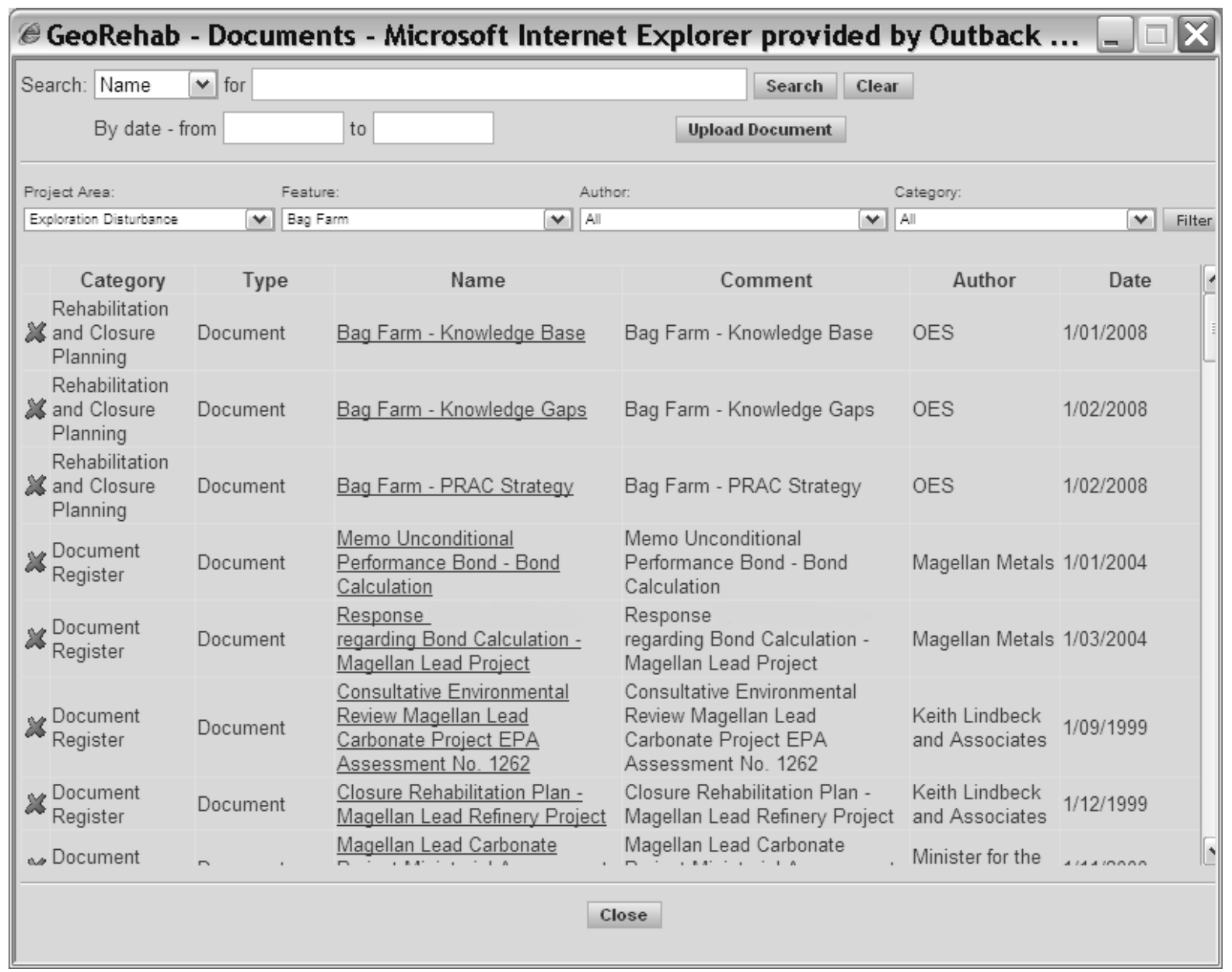

\section{Figure 4 Document search function in the Company's PRAC ${ }^{\circledR}$ system}

\subsection{Example - the Bag Farm}

An example of the planning process is given here for the Bag Farm. The exploration Bag Farm is located on one of the mining tenements. The area is used to store sample bags from exploration undertaken prior to and during mine operations. No topsoil appeared to have been removed from the area prior to storage of the exploration bags.

Given this information three knowledge gaps were identified in relation to:

- Soil chemistry of the Bag Farm (chemistry and geochemistry investigation).

- Potential implications for contaminated sites legislation (potential contaminated sites investigation).

- Understanding the long term land use requirements (closure management investigation). 
Based on the current level of understanding as detailed in the knowledge base the rehabilitation task for the bag farm would involve:

- Removal and appropriate disposal of all sample bags and drill spoil.

- Removal of any impacted soils for disposal.

- Re-spreading stockpiled topsoil and/or vegetation mulch where available.

- Lightly ripping compacted areas.

- Seeding with local provenance seed where required.

Closing the knowledge gaps by completion of the investigative tasks outlined above will enable this rehabilitation plan to be finalised or adapted as required.

Exploration bags are designed to break down over time; therefore the potential for spills from exploration bags is considered high. Knowledge of soil chemistry at the Bag Farm (detailed as a knowledge gap) is required to establish to what degree spills from the exploration bags must be removed. Maintaining existing topsoil and limiting the volumes of soil requiring removal would reduce closure costs.

Validation sampling results from soil within the Bag Farm should be compared against agreed closure standards, particularly for lead, to ensure compliance.

One of the advantages of progressive rehabilitation and closure planning is that areas no longer required can be closed out. Often this may be possible prior to the actual closure of the mine, which allows costs associated with closure to be split over a number of years and also allows for progressive reduction in liabilities.

The progressive closure and rehabilitation strategy for the Bag Farm assessed the priority for these tasks and ordered them accordingly (Figure 3). For all features, outcomes of the investigative tasks are incorporated back into the closure system, including adaptation of the rehabilitation strategy as required.

\section{Conclusion}

Current uncertainty within economic markets has seen unplanned closures of numerous mining operations within Australia and overseas; possibly of mines that would not have been developed if the previous buoyant economic times and high product demand had not existed. It is likely this closure trend will continue until confidence returns to markets and commodity prices rebound. Uncertain times are a good trial of organisations not be adequately prepared for effective closure and rehabilitation of their operations. Consequences of being unprepared for closure include high risk issues going unidentified, ongoing financial liabilities, delaying or forfeiting of tenement bonds, and loss of reputation with regulators and other key stakeholders. Progressive rehabilitation and closure planning is critical for all mining operations, however particularly during times of instability it assists companies in reducing the risk and consequences of unplanned closure.

Progressive closure and rehabilitation planning has already facilitated the Company's drive for performance monitoring of their landforms during operations, instead of at the end of mine life. This will result in performance data being available for analysing the effectiveness of the rehabilitation programme, thus enabling well informed decisions to be made with regard to future rehabilitation designs and procedures. This monitoring data will be used to demonstrate performance against closure criteria, which will form the basis for future reductions in liability held against the mine.

The Company recognised that progressive mine closure planning will result in a number of benefits to its operation, hence the application of this unique web-based GIS system. Benefits will be seen from a financial perspective through better planning leading to enhanced efficiency and improved cash flow. From an environmental perspective, progressive planning has facilitated ongoing feedback of environmental performance through monitoring, resulting in enhanced rehabilitation outcomes. The Company believes the financial and time commitments it has made in preparing and implementing a progressive mine closure strategy via this system, will result in improved ability in estimating closure liabilities and improved ability to demonstrate closure planning and rehabilitation performance to key stakeholders. 


\section{References}

Australian and New Zealand Minerals and Energy Council and Minerals Council of Australia (ANZMEC/MCA) (2000) Strategic framework for mine closure, National Library of Australia Catalogue Data, Australian and New Zealand Minerals and Energy Council and Minerals Council of Australia, Sec. 6, pp. 35-37.

Australian Government Department of Industry, Tourism and Resources (DITR) (2006) Mine closure and completion Leading practice sustainable development program for the mining industry, October 2006, Commonwealth of Australia, p. 3.

D.E. Cooper and Associates Pty Ltd (1999) Magellan Lead Project - Proposed Tailings Storage and Waste Rock Stockpile - Technical Report, Tailings Management Notice of Intent, Project No 95-98, July, pp. 4-5.

Environment Australia (2002) Mine Decommissioning, One Booklet in Series Best Practice Environmental Management in Mining, July 2002, Sec. 6, Commonwealth of Australia.

Keith Lindbeck and Associates (1999) Consultative Environmental Review Magellan Lead Carbonate Project (EPA Assessment No. 1262), Mine and Concentrator near Wiluna with transport and export of Concentrate through the Port of Geraldton, September, pp. 32-45.

Lacy, H.W.B., Koontz, D.V., Lamont, R., Henderson, D.W. and Boisvert, M.B. (2002) Progressive Rehabilitation Locking the idea into a system to deliver results, In Proceedings Workshop on Environmental Management in Arid and Semi-Arid areas, 29-31 May 2002, Kalgoorlie, Australia, Goldfields Land Rehabilitation Group, pp. 113-118.

Lacy, H.W.B. and Koontz, D.V. (2002) Progressive Mine Rehabilitation Systems Taking the Static Activity of Mine Closure into Dynamic and Auditable System, In Proceedings Workshop on Sustainable Mine Closure, Sec. 5, 23-24 October 2002, Adelaide, Australia.

Laurence, D.C. (2002) Optimising mine closure outcomes for the community - Lessons learnt, Vol. 17, No 1, Minerals and Energy, Raw Materials Group, pp. 27-34.

Mackenzie, S., Mitchell, I. and McGuire, C. (2008) Progressive rehabilitation and closure planning using GIS-based software at the Mungari Project, Western Australia, In Proceedings Goldfields Environmental Management Group Workshop, 21-23 May 2008, Kalgoorlie, Australia, pp. 71-79.

PricewaterhouseCoopers (PWC) (2007) Financial reporting in the mining industry - International Financial Reporting Standards, June 2007, Section 9 Closure and Environmental Liabilities, Energy, Utilities and Mining, PricewaterhouseCoopers, pp. 56-59. 